\title{
Review
}

\section{Hepatitis C virus recurrence after liver transplantation}

\begin{abstract}
Summary
Cirrhosis due to hepatitis $\mathrm{C}$ virus (HCV) is now the most common indication of liver transplantation in Western Europe and the United States. In the absence of effective prophylaxis, recurrent HCV infection is almost inevitable. Though the natural history and intermediate term outcome of recurrent HCV are now better documented, those factors which may influence the recurrence of hepatitis and consequent progression of graft disease remain unclear. Interferon (IFN) as a sole agent for the treatment of recurrent infection has proved unsatisfactory. Early intervention with a combination of IFN and ribavirin seems promising, and this approach may prevent or delay progression of HCV related graft disease after liver transplantation.
\end{abstract}

\section{Introduction}

Since the identification of hepatitis C virus (HCV) in $1989,{ }^{1}$ it soon became evident that hepatitis $\mathrm{C}$ represents a major public health problem in Europe and in the United States. Chronic infection progresses to cirrhosis in at least $20 \%$ of patients, and liver failure will occur in more than $10 \%$ of infected patients after 20 years of carrying the virus. ${ }^{2} \mathrm{HCV}$ infection is an established risk factor for hepatocellular carcinoma. ${ }^{3}$ Unfortunately, the results of interferon (IFN) treatment are disappointing, and a sustained response will be observed in fewer than $20 \%$ of patients treated. ${ }^{4}$ Hence, available treatment may have little impact on disease progression for the majority of patients, and $\mathrm{HCV}$ will become an increasingly important indication for liver transplantation. Already, $15-20 \%$ of European and North American transplant candidates are infected with $\mathrm{HCV}^{5}$ and 1859 European patients have been transplanted for HCV associated cirrhosis since $1985 .{ }^{\circ}$

As a result of improved virus detection methods, progress has been made in the understanding of HCV recurrence after transplantation. For example, the development of advanced antibody tests has reduced the number of false positive results. More importantly the development of molecular biological techniques has permitted better appraisal of replication dynamics. The clinical manifestations of recurrent $\mathrm{HCV}$ are extremely variable, and range from total absence of symptoms with normal biochemistry to severe cholestatic hepatitis with rapid progression to cirrhosis. Our understanding of the pathogenic mechanisms which underlie this clinical diversity remains unsatisfactory. The management of recurrent infection and the use of antiviral therapy in the context of transplantation therefore remain a challenge.

In this review we discuss the diagnosis, natural history, pathogenesis, and treatment of HCV recurrence after liver transplantaion.

\section{Diagnosis of recurrent $\mathrm{HCV}$ infection}

HCV infection of the liver transplant recipient represents acquired infection or recurrent infection, or both. Genetic sequencing of variable regions of the viral genome permits comparison of pre- and post-transplant HCV species, and distinguishes recurrent from acquired infection. ${ }^{7}$ Circulating virus, and virus harboured in extrahepatic sites, provides clues for the type of graft infection. For instance, peripheral blood mononuclear cells have been shown to contain negative strand viral RNA, the replicative intermediate of the viral genome. ${ }^{8}$

Initial studies relying on second generation serological tests understimated the frequency of recurrent $\mathrm{HCV}$ infection. Among patients who are HCV positive before transplantation, the antibody seroprevalence after transplantation by first and second generation assays varied from 41 to $83 \% .^{{ }^{9-11}}$ Loss of antibody seropositivity is probably the consequence of immunosuppressive treatment. Poterucha et al confirmed the inferior sensitivity of serological tests, compared with PCR detection of viral RNA, for the diagnosis of recurrent HCV in the transplant setting. ${ }^{12}$ In fact, HCV RNA can be detected in most HCV RNA positive liver transplant recipients after transpantation. ${ }^{13-16}$ Viral RNA can be detected in serum and liver during the first post-transplant month. ${ }^{17}$

Reliable quantitation of viral RNA using techniques such as the branched chain DNA assay may also prove to be useful for the investigation of recurrent infection after transplantation. For instance, the lobular hepatitis observed after recurrent infection may be associated with an extremely high serum viral titre. ${ }^{18}$ Therefore, measurement of viral titres may permit the early diagnosis of recurrent hepatitis, and may influence subsequent patient management (including the early administration and subsequent adjustment of antiviral treatment).

More recently it has been suggested that the detection of IgM anti-HCV core may be a sensitive marker of viral recurrence, independent of the level of immunosupression. Its measurement might provide early evidence of graft hepatitis. $^{19}$

\section{Natural history of $\mathrm{HCV}$ recurrence after transplantation}

As transplanted patients now expect to survive long term, the management of recurrent HCV has assumed greater importance. Viraemia can exist in the absence of histological lesions $\mathrm{s}^{20}$ and the HCV RNA titre may not reflect the histological changes. Recurrent infection is not necessarily associated with graft hepatitis, which may still be absent in as many as $50 \%$ of patients within two years posttransplant. ${ }^{21}{ }^{22}$ Graft reinfection is generally initiated by a lobular hepatitis, frequently asymptomatic and occurring commonly between the first and fourth months after transplantation. This hepatitis resolves very occasionally but most often evolves into a chronic hepatitis. ${ }^{23}$ Evolution into severe hepatitis with graft loss is also well documented ${ }^{2124}$ and early histological recurrence may be associated with an increased risk of disease progression. ${ }^{25}$ Liver cell necrosis with conspicuous increases in alanine aminotranferase activity is not a constant finding, so prospective histological surveillance is required for the management of patients who were transplanted for $\mathrm{HCV}^{21}$ Indeed, there is a poor correlation between serum aminotranferase values and the severity of graft damage. ${ }^{22}$

Early studies suggested that the survival of patients transplanted for HCV was not inferior to the survival of

Abbreviations used in this paper: $\mathrm{HCV}$, hepatitis $\mathrm{C}$ virus; IFN, interferon; HBV, hepatitis B virus; CMV, cytomegalovirus. 
Table 1 Long term natural history of HCV recurrence after liver transplantation

\begin{tabular}{|c|c|c|c|c|c|c|c|c|}
\hline \multirow[b]{2}{*}{ Study } & \multirow{2}{*}{$\begin{array}{l}\text { Duration of } \\
\text { follow up }(y)\end{array}$} & \multicolumn{3}{|l|}{ Survival (\%) } & \multicolumn{3}{|c|}{ Graft loss related to HCV recurrence (n) } & \multirow{2}{*}{$\begin{array}{l}\text { Cirrhosis/cholestatic } \\
\text { hepatitis (n) }\end{array}$} \\
\hline & & HCV group & Control group & p Value & HCV group & Control group & p Value & \\
\hline Gane $e t a l^{27}$ & 5 & 70 & 69 & NS & $8 / 149$ & - & - & $10 / 149$ \\
\hline \multirow[t]{2}{*}{ Bôker $e t a l^{28}$} & 5 & 62 & 57 & NS & $0 / 61$ & - & - & $0 / 61$ \\
\hline & 10 & 62 & 52 & NS & $0 / 61$ & - & - & $1 / 61$ \\
\hline
\end{tabular}

Note: patient survival is comparable in the HCV and control groups, but the rate of graft loss related to HCV infection (different in the two studies, $5.4 \% v 0 \%$ ) was not compared with the controls.

patients transplanted for other liver conditions. For instance, Feray et al reported that the five year survival was not significantly different from that observed for a control group $(80 v 89 \%){ }^{23}$ This observation was not supported by other investigators who described inferior graft (56 $v 74 \%$ ) and patient (66 $v 81 \%$ ) survival of patients with $\mathrm{HCV}$ when compared with a control group. The same investigators also found a higher regraft rate for the HCV infected patients. ${ }^{26}$ Gane et al found no significant difference in the five year survival of patients transplanted for $\mathrm{HCV}$ compared with other indications (70 $v 69 \%$ ) (table 1 ). The incidence of cirrhosis was $8 \%$ after five years and eight of 149 patients had lost their grafts as a direct result of graft reinfection. ${ }^{27}$ The same study showed, as did other series, ${ }^{26}{ }^{29}$ that the risk of significant bacterial infection may be increased when transplantation is undertaken for $\mathrm{HCV}$ infection. The study by Boker et al could not demonstrate that recurrent HCV had a significant impact on mortality during the first post-transplant decade. In that analysis, a single patient developed cirrhosis during the first two posttransplant years, but none lost the graft as a direct result of recurrent viral infection. ${ }^{28}$

As for hepatitis $B$ virus (HBV) infection, a rapidly progressive form of fibrosing cholestatic hepatitis has been associated with HCV recurrence in some patients. Described initially in a heart transplant recipient who acquired $\mathrm{HCV}$ from the donor, ${ }^{30}$ it has been reported in as many as $8 \%$ of patients with $\mathrm{HCV}$ recurrence. The prognosis is poor and most affected patients require early regrafting. ${ }^{31}$ No data have been published until recently on the efficacy of antiviral treatment in this form of $\mathrm{HCV}$ recurrence.

Clearly, HCV recurrence can precipate early graft loss and is associated with the development of cirrhosis in some patients. The impact of recurrent infection is underestimated by studies with short term follow up, and the true impact may not be observed until the second decade after tranpslantation. Although reinfection is associated with minimal graft damage for a number of patients, others have aggressive infection. It seems likely that those studies which failed to show an impact of recurrent infection on graft and patient survival may require larger numbers of patients, with longer follow up or better selected controls.

\section{Pathogenesis of hepatitis after $\mathrm{HCV}$ recurrence}

The variable consequences of liver disease associated with recurrent $\mathrm{HCV}$ infection suggest that different viral and/or host factors are important in determining the clinical outcome, but their impact remains unclear.

The serum viral titre seems to be higher after transplantation, probably as a consequence of immunosuppression. There is no clear correlation between viral titre and histological changes, ${ }^{20}$ suggesting that HCV may not be directly cytopathic. A potentially important factor may be the effect of genotype on disease recurrence. The influence of viral genotype on disease progression and the risk of developing hepatocarcinoma in the immunocompetent patient are uncertain. The liver transplantation model where the duration of infection is known might permit an improved understanding of the clinical relevance of genotypes to dis- ease progression. Initial studies suggested that genotype $1 \mathrm{~b}$ was associated with more aggressive recurrence. ${ }^{1632}$ However, the predominance of genotype $1 \mathrm{~b}$ in the transplanted population may have influenced that observation. In Gane et al's study the presence of genotype 1b seemed to be associated with an unfavourable clinical course with more severe hepatitis and cirrhosis. ${ }^{27}$ These findings were not supported by Wright et al who examined a cohort of 124 patients that included equivalent numbers of genotypes $1 \mathrm{~b}$ and $1 \mathrm{a} \cdot{ }^{14}$ Furthermore, genotype $1 \mathrm{a}$ was claimed to be predominant among patients regrafted for recurrent $\mathrm{HCV}$ infection ${ }^{33}$ and might be most frequently associated with the development of fibrosing cholestatic hepatitis. ${ }^{31}$ Little is known about the influence of viral quasispecies on the outcome of recurrent $\mathrm{HCV}$ infection after transplantation. It seems that the heterogeneity of viral quasispecies decreases after transplantation probably because of the decreased immunity mediated selective pressure that results from immunosuppressive therapy. ${ }^{34} 35$ These results can only be considered preliminary and more patients must be studied to address this issue. The potential impact of hepatitis $G$ virus coinfection on the clinical course of HCV infected recipients has also been studied and there seems to be no association between hepatitis $G$ virus co-infection and the severity of liver disease after transplantation. ${ }^{36-38}$

It is likely that other immune responses influence the severity of recurrent $\mathrm{HCV}$ infection. Rejection, and its management, may be important determinants of outcome. Thus, according to Sheiner et al multiple rejection episodes are frequently associated with recurrent hepatitis. Corticosteroid resistant rejection requiring OKT3 treatment was associated with early and frequent recurrence. ${ }^{39}$ Such observations might encourage the preference for tacrolimus as primary immunosuppression for patients transplanted for $\mathrm{HCV}$ as its has been shown to diminish the requirement for corticosteroids in comparison with cyclosporin treated patients. ${ }^{40}$ However, Gane et al found no difference between the frequency and severity of recurrent $\mathrm{HCV}$ infection in tacrolimus treated compared with cyclosporin treated patients. ${ }^{27}$ The impact of OKT3 induction on recurrent $\mathrm{HCV}$ infection is also disputed. ${ }^{41}$ The impact of rejection and immunosuppression on $\mathrm{HCV}$ recurrence needs to be carefully defined in future studies. It seems likely that these related factors act by influencing the immune response, rather than by simply increasing viral titre. In addition, the nature of the immune response, with deviation towards a Th2 cytokine profile and diminution of the inflammatory reaction, might favour a more cytopathic effect for $\mathrm{HCV}$, as has been observed for other infectious diseases. ${ }^{42}$

Gretch et al found that the donor/recipient HLA match at the DQ loci is associated with histological recurrence. ${ }^{43}$ A similar observation has been for HBV recurrence, ${ }^{44}$ but this observation was not upheld by Gane et al in their analysis of HCV recurrence.

The possible relation between cytomegaolovirus (CMV) viraemia and $\mathrm{HCV}$ recurrence has also been studied. ${ }^{45}$ Patients transplanted for HCV who developed CMV viraemia had a significantly greater risk of severe recurrent 
hepatitis. As CMV viraemia is often associated with more rejection episodes and increased immunosuppression, it is difficult to determine the direct impact of CMV infection on $\mathrm{HCV}$ recurrence. CMV infection may be associated with high levels of tumour necrosis factor $\alpha$, which may in turn be a mediator in the pathogenesis of $\mathrm{HCV}$ infection. ${ }^{46}$

\section{Treatment of $\mathrm{HCV}$ recurrence}

TREATMENT OF ESTABLISHED INFECTION

The use of IFN monotherapy for recurrent HCV infection has been described in three published studies (table 2). The first study described 11 patients treated for six months at a dose of 3 million units thrice weekly. A biochemical response was observed for a single patient, and no rejection was observed. ${ }^{47}$ Wright et al monitored patients' response to four months' treatment with IFN $\alpha-2 b$ at a dose of 3 million units thrice weekly. A biochemical response was observed in $28 \%$, but a completely negative PCR result was not achieved for any, and post-treatment titres were not significantly reduced from those before treatment. In that study, a biochemical response was predicted by low serum bilirubin, low viral titre, and a long interval between transplantation and the start of treatment. No histological improvement was observed after treatment. A single episode of steroid responsive graft rejection was observed. ${ }^{48}$

In contrast, Feray and colleagues ${ }^{49}$ reported significant IFN associated morbidity. Fourteen patients were treated for six months at a dose of 3 million units thrice weekly. Chronic rejection developed in 35\% of the treated group compared with only $3 \%$ in a non-treated group. The biochemical response rate was $23 \%$, and a reduction in viral titre was achieved in $57 \%$ of the treated patients. Histological improvement was observed in two patients.

These observations do not support the widespread use of IFN monotherapy for treatment of established graft infection.

Ribavirin has also been used as monotherapy for recurrent HCV. ${ }^{50}{ }^{51}$ Two studies of a total of 16 patients have been reported, and the results appear concordant. Normalisation of aminotransferase values was observed in $50 \%$ of treated patients, which reversed on discontinuation of treatment. Viral titres may diminish, but virus can always be detected during treatment. Histological improvement may be observed in patients with a biochemical response. ${ }^{50}$ No episodes of rejection were observed and side effects seemed comparable with those experienced by an immunocompetent population.

Combination IFN-ribavirin, followed by ribavirin alone, may provide an alternative approach (table 2). ${ }^{52}$ We have treated 21 patients using this protocol. After six months of combination therapy, the biochemical response rate was $100 \%$, and $48 \%$ of treated patients were serum PCR negative. During subsequent ribavirin monotherapy, aminotransferase values remained normal for all but one of 18 patients who were tolerant of ribavirin. The improvement in histological activity, observed for all patients after six months of combination therapy, was maintained by all but one patient who remained on ribavirin for a further six months. Three patients with pre-existing renal insufficiency developed anaemia of sufficient severity that ribavi- rin had to be stopped. Rejection was not observed during this study. The immunosuppressive effect of ribavirin may influence the development of rejection during combination therapy. ${ }^{53} 54$

Patients with graft failure associated with recurrent $\mathrm{HCV}$ infection might be considered for regrafting. Few data are available, but those of Sheiner et al suggest that regrafting should be undertaken before the developement of renal insufficiency and infectious complications. ${ }^{33}$ It is noteworthy that in this series the prevalence of genotype $1 \mathrm{a}$ in patients considered for regrafting was high, compared with the overall prevalence of patients transplanted for HCV cirrhosis. Among the nine patients who survived the postoperative period, a single patient developed fatal $\mathrm{HCV}$ recurrence. Thus, it seems that regrafting is a realistic option as long as it is considered in due time.

\section{PROPHYLACTIC TREATMENT}

The use of IFN before transplantation poses two problems: tolerance of IFN is frequently poor in patients with decompensated cirrhosis, and efficacy is mostly lacking at this advanced stage. However, in our experience (unpublished data), which is similar to that of Van Thiel et al, ${ }^{55}$ the clearance of HCV RNA before transplantation helps to prevent HCV recurrence after transplantation.

Another theoretical approach, currently impractical, is immunoprophylaxis with specific anti-HCV immunoglobulin, similar to the prevention of HBV infection. However, immunoprophylaxis was not shown to be protective in an animal model. ${ }^{56}$ Nevertheless, a lower rate of $\mathrm{HCV}$ recurrence has been reported for patients receiving anti-HBs hyperimmune globulin. ${ }^{57}$ These results, suggesting a potentially protective role for anti-HCV antibodies, are difficult to interpret in the context of a dual viral infection (HBV and HCV). In addition, the anti-HCV titre of such preparations is likely to be low as anti-HCV positive blood donors are excluded from donating blood.

\section{Conclusion}

Recurent HCV infection and hepatitis remain an unresolved challenge in liver transplantation. Although HCV reinfection is universal, only $50 \%$ of patients seem to develop chronic hepatitis during short term follow up. The prevalence increases as the length of follow up increases. The impact of HCV recurrence on long term survival, the risk of developing cirrhosis and graft loss warrants further evaluation. The subgroup of patients who develop fibrosing cholestatic hepatitis deserves special attention. The natural history of HCV recurrence is better understood as a result of retrospective studies, but only prospective studies will help to clarify the virological and histological course of recurrent infection. An improved understanding of immune responses to $\mathrm{HCV}$ infection might explain why some patients develop recurrent hepatitis, yet others experience viraemia without significant graft pathology. With respect to antiviral treatment, IFN has little efficacy and may be associated with the developement of acute and chronic rejection. Early intervention with combination IFN-ribavirin therapy may be a promising alternative, but this requires confirmation in prospective

Table 2 Treatment of HCV recurrence

\begin{tabular}{|c|c|c|c|c|c|c|}
\hline Study & Treatement & $\begin{array}{l}\text { No of } \\
\text { patients }\end{array}$ & $\begin{array}{l}\text { Biochemical } \\
\text { responders (\%) }\end{array}$ & $\begin{array}{l}\text { PCR negative } \\
(\%)\end{array}$ & $\begin{array}{l}\text { Histological } \\
\text { improvement (\%) }\end{array}$ & Rejection (\%) \\
\hline Wright et $a l^{47}$ & IFN $3 M U \times 3 / W$ (6 months) & 11 & 9 & 0 & 0 & 0 \\
\hline Wright et al ${ }^{48}$ & IFN $3 M U \times 3 / W(4$ months) & 18 & 28 & 0 & 0 & 4 \\
\hline Feray et al ${ }^{49}$ & IFN 3 MU $\times 3 / W$ ( 6 months) & 14 & 23 & 0 & 14 & 35 \\
\hline Cattral et al ${ }^{50}$ & Ribavirin (6 months) & 9 & 44 & 0 & 22 & 0 \\
\hline Gane et al ${ }^{51}$ & Ribavirin ( 6 months) & 7 & 57 & 0 & 57 & 0 \\
\hline Bizollon et al ${ }^{52}$ & IFN $3 M U \times 3 / \mathrm{W}$ + ribavirin ( 6 months) & 21 & 100 & 48 & 100 & 0 \\
\hline
\end{tabular}


studies. The potential benefit of maintenance ribavirin treatment needs to be established. The alternative approach may to aim at the eradication of infection before transplantation, but this option will require safer and better treatment than IFN. Finally, the development of xenotransplantation and the use of organs resistant to human pathogens like $\mathrm{HCV}$ may be a possibility for the distant future.

T BIZOLLON C DUCERF

C TREPO

Hepatology and Liver Transplantation Unit, Hôtel-Dieu Croix-Rousse,

Lyon,

France

D MUTIMER

Liver and Hepatobiliary Unit,

Queen Elisabeth Hospital,

Birmingham, UK

Correpondence to: Professor C Trepo, Hepatology Unit, Hôtel-Dieu 69288 Lyon Cedex 02, France (email : trepo@lyon151.inserm.fr).

1 Kuo G, Choo QL, Alter HJ, et al. An assay for circulating antibodies to a major etiologic virus of human non-A non-B hepatitis. Science major etiologic

2 Di Bisceglie AM, Goodmann ZD, Ishak KG, et al. Long term clinical and histopathological follow up of chronic post-transfusion hepatitis. Hepatology 1991;14:969-74.

3 Di Bisciglie AM. Hepatitis C and hepatocellular carcinoma. Semin Liver Dis 1995;15:64-9.

4 Tine F, Magin S, Craxi A, et al. Interferon for non-A, non-B chronic hepatitis, a meta-analysis of randomised clinical trials. F Hepatol 1991;13:192-9.

5 Ascher NL, Lake JR, Emond J, et al. Liver transplantation for hepatitis C virus-related cirrhosis. Consensus conference on indications of liver transplantation. Hepatology 1994;20:24-7S.

6 European Liver Transplant Registry (June 1994). Centre Hépato-Biliaire, Hopital Paul Brousse, Villejuif, France, 1994

7 Weiner AJ, Brauer MJ, Rosenblatt J, et al. Variable and hypervariable domains are found in the region of HCV corresponding to the flavivirus envelope and NS1 proteins and the pestivirus envelope glycoprotéins. Virology 1991;180:842-8.

8 Saleh MG, Tibbs CJ, Pereira LMMB, et al. HCV-RNA in peripheral blood mononuclear cells but not in liver: evidence for extra-hepatic $\mathrm{HCV}$ replicamononuclear cells but not in liver: evidence for extra-hepatic HCV replica-
tion in the absence of extra-hepatic replication [abstract]. Hepatology 1993; tion in the

9 El-Ashmany L, Hassanein T, Gavaler JS, et al. Prevalence of hepatitis C virus antibody in a liver tranplantation population. Dig Dis Sci 1992;37:11 10-15.

10 Knoop M, Bechstein WO, Blumhardt G, et al. Recurrent hepatitis C infection after orthotopic liver transplantation. Transplant Proc 1995;27:120810.

11 Read AE, Donegan E, Lake J, et al. Hepatitis C in patients undergoing liver transplantation. Ann Intern Med 1991;114:282-4.

12 Potuchera JJ, Rakela J, Lumeng L, et al. Diagnosis of chronic hepatitis C after transplantation by the detection of viral sequences with polymerase chain reaction. Hepatology 1992;15:42-5.

13 Feray C, Samuel D, Thiers V, et al. Reinfection of liver graft by hepatitis C virus after liver transplantation. I Clin Invest 1992;89:1361-5.

14 Zhou S, Terrault NA, Ferrell L, et al. Severity of liver disease in liver transplantation recipients with hepatitis $\mathrm{C}$ virus infection: relationship to genoplantation recipients with hepatitis $\mathrm{C}$ virus infection:
type and level of viremia. Hepatology 1996;24:1041-6.

15 Wright TL, Donegan E, Hsu HH, et al. Recurrent and acquired hepatitic viral infection in liver transplant recipients. Gastroenterology 1992;103:31722.

16 Weinstein JS, Poterucha JJ, Zein N, et al. Epidemiology and natural history of hepatitis C infections in liver transplant recipients. If Hepatol 1995;22(suppl 1):154-9.

17 König V, Bauditz J, Lobeck $\mathrm{H}$, et al. Hepatitis $\mathrm{C}$ virus reinfection in allografts after orthotopic liver transplantation. Hepatology 1992;16:113743.

18 Gane EJ, Naoumov NV, Qian K-P, et al. A longitudinal analysis of hepatitis C virus replication following liver transplantation. Gastroenterology 1996;110:167-77.

19 Negro F, Giostra E, Rubbia-Brandt L, et al. IgM anti-hepatitis core antibody as marker of recurrent hepatitis $\mathrm{C}$ after liver transplantation [abstract]. Hepatology 1997;26:213A.

20 Chazouilleres O, Kim M, Combs C, et al. Quantitation of hepatitis C virus RNA in liver transplant recipients. Gastroenterology 1994;106:994-9.

21 Ferrell L, Wright TL, Roberts J, et al. Hepatitis C viral infection in liver transplant recipients. Hepatology 1992;16:865-76.

22 Loinaz C, Lumbreras C, Gonzalez-Pinto I, et al. high incidence of post-transplant hepatitis and chronic rejection associated with hepatitis C post-transplant hepatitis and chronic rejection associated with hepatitis C
virus infection in liver transplant recipients. Transplant Proc 1995;27:121718.

23 Feray C, Gigou M, Samuel D, et al. The course of hepatitis C virus infection after liver transplantation. Hepatology 1994;20:1137-43.
24 Martin P, Munoz SJ, Di Bisceglie AM, et al. Recurrence of hepatitis C virus infection after orthotopic liver transplantation. Hepatology 1991;13:719-21. 25 Shuhart MC, Bronner MP, Gretch DR, et al. Histological and clinical outcome after liver transplantation for hepatitis C. Hepatology 1997;26:164652 .

26 Casavilla A, Mateo R, Rakela J, et al. Impact of hepatitis C virus infection on survival following primary liver transplantation under FK506 [abstract] Hepatology 1994;20:133A

27 Gane EJ, Portmann BC, Naoumov NV, et al. Long term outcome of hepatitis C infection after liver transplantation. $N$ Engl 7 Med 1996;334:815-20.

28 Boker KHW, Dalley G, Bahr MJ, et al. Long-term outcome of hepatitis C virus infection after liver transplantation. Hepatology 1997;25:203-10.

29 Singh N, Gayowsky T, Wagener MM, et al. Increased infections in liver transplant recipients with recurrent hepatitis $\mathrm{C}$ virus hepatitis. Transplantation 1996:61:402-6.

30 Lim HL, Lau GKK, Davis GL, et al. Cholestatic hepatitis leading to hepatic failure in a patient with organ-transmitted hepatitis $\mathrm{C}$ virus infection. Gastroenterology 1994;106:248-5

31 Schluger LK, Sheiner PA, Thung SN, et al. Severe recurrent cholestatic hepatitis C following orthotopic liver transplantation. Hepatology 1996;23: 971-6.

32 Feray C, Gigou M, Samuel D, et al. Influence of the genotypes of hepatitis C virus on the severity of recurrent liver disease after liver transplantation. Gastroenterology 1995;108:1088-96.

33 Sheiner PA, Sschluger LK, Emre S, et al. Retransplantation for recurrent hepatitis C. Liver Tranplant Surg 1997;3:130-6.

34 Martell M, Esteban JI, Quer J, et al. Dynamic behavior of hepatitis C virus quasispecies in patients undergoing orthotopic liver transplantation. $\mathcal{F}$ Virol

35 Gonzales-Peralta RP, Naoumov NV, Liu WZ, et al. Evolution of hepatitis C virus quasispecies heterogeneity after liver transplantation [abstract]. Hepatology 1996;23(suppl):670A.

36 Berenguer M, Terrault NA, Piatak M, et al. Hepatitis G virus infection in patients with hepatitis $\mathrm{C}$ virus infection undergoing liver transplantation. Gastroenterology 1996;111:1569-75.

37 Colter SJ, Gretch DR, Bronner MP, et al. Hepatitis G virus coinfection does not alter the course of recurrent hepatitis $\mathrm{C}$ virus infection in liver transplant recipients. Hepatology 1997;26:432-6.

38 Bizollon T, Guichard S, Si Ahmed SN, et al. Impact of hepatitis G virus co-infection on the course of hepatitis $\mathrm{C}$ virus infection before and after liver transplantation. ₹ Hepatol 1998:29:893-900.

39 Sheiner PA, Schwartz ME, Mor E, et al. Severe or multiple rejection episodes are associated with early recurrence of hepatitis $C$ after orthotopic liver transplantation. Hepatology 1995;21:30-4.

40 The US Multicenter FK506 liver study group. A comparison of tacrolimus (FK506) and cyclosporine for immunosuppression in liver transplantation. N Engl f Med 1994;331:1110-15.

41 Rosen HR, Martin P, Shackleton CR, et al. OKT3 use associated with diminshed graft and patient survival in patients transplanted for chronic hepatitis C [abstract]. Hepatology 1996;22:132A.

42 Ascher NL. The role of the host immune state in recurrent hepatitis C. Liver Transplant Surg 1997;3:179-80.

43 Gretch D, Wile M, Gaur L, et al. Donor-recipient match at the HLA-DQB locus is associated with recrudescence of chronic hepatitis following liver transplantation for end-stage hepatitis C [abstract]. Hepatology 1993; 18(suppl): $18 \mathrm{~A}$

44 Calmus Y, Hannoun L, Dousset B, et al. HLA class I matching is responsible for the hepatic lesions in recurrent viral hepatitis B after liver transplantation. Transplant Proc 1990;22:2311-13

45 Rosen HR, Chou S, Corless CL, et al. Cytomegalovirus viremia. Risk factor for allograft cirrhosis after liver transplantation for hepatitis C. Transplantation 1997;64:721-6.

46 Larrea E, Garcia N, Quian C, et al. Tumor necrosis factor-alpha gene expression and the response to inteferon in chronic hepatitis C. Hepatology

47 Wright HI, Gavaler JS, Van Thiel DH. Preliminary experience with alpha-2b-interferon therapy of viral hepatitis in liver allograft recipients. Transplantation 1992:53:121-4.

48 Wright TL, Combs C, Kim M, et al. Interferon alpha therapy for hepatitis C virus infection after liver transplantation. Hepatology 1994;20:773-9.

49 Feray C, Samuel D, Gigou M, et al. An open trial of IFN alpha recombinant for hepatitis $\mathrm{C}$ after liver transplantation: antiviral effects and risk of rejection. Hepatology 1995;22:1084-9.

50 Cattral MS, Krajden M, Wanless IR, et al. A pilot study of ribavirin therapy for recurrent hepatitis C virus infection after liver transplantation. Transplantation 1996;61:1483-8.

51 Gane EJ, Tibbs CJ, Ramage JK, et al. Ribavirin therapy for hepatitis C infection following liver transplantation. Transplant Int 1995;8:61-4.

52 Bizollon T, Palazzo U, Ducerf C, et al. Pilot study of the combination of alpha interferon and ribavirin as therapy of recurrent hepatitis $\mathrm{C}$ after liver transplantation. Hepatology 1997;26:500-4.

53 Heagy W, Crumpacker C, Lopez PA, et al. Inhibition of immune functions by antiviral drugs. I Clin Invest 1991;87:1916-24.

54 Jolley W, Sharma B, Chami R, et al. Long-term skin allograft survival by combined therapy with suboptimal dose of cyclosporin and ribavirin. Transplant Proc 1988;20:703-6.

55 Van Thiel DH, Faruki H, Fagioli H, et al. Successful treatment of end-stage liver disease due to hepatitis C prior to liver transplantation [abstract]. Hepatology 1994;20:137A

56 Krawczynski K, Alter MJ, Tankersley DL, et al. Studies on protective efficacy of hepatitis $\mathrm{C}$ immunoglobulins in experimental hepatitis $\mathrm{C}$ infection [abstract]. Hepatology 1993;17:110A.

57 Feray C, Samuel D, Gigou M, et al. Reduced incidence of recurrent and acuqired infection by HCV after liver transplantation in patients receiving immunoglobulins [abstract]. Hepatology 1994;20:131A. 